Paper published in:

A.W. Bruno, D. Gallipoli (2019).

A coupled hydromechanical bounding surface model predicting the hysteretic behaviour of unsaturated soils.

Computers and Geotechnics, 110: 287-295

https://doi.org/10.1016/i.compgeo.2019.02.025

\title{
A COUPLED HYDROMECHANICAL BOUNDING SURFACE MODEL PREDICTING THE HYSTERETIC BEHAVIOUR OF UNSATURATED SOILS
}

\author{
Agostino Walter Bruno ${ }^{1}$ and Domenico Gallipoli ${ }^{2}$ \\ ${ }^{1}$ School of Engineering, Geotechnics and Structures, Newcastle University, United Kingdom \\ ${ }^{2}$ Laboratoire SIAME, Fédération IPRA, Université de Pau et des Pays de l'Adour, 64600 Anglet, France.
}

DATE OF SUBMISSION: 30/12/2018

NUMBER OF WORDS: 5819

NUMBER OF TABLES: 1

NUMBER OF FIGURES: 13

CORRESPONDING AUTHOR: Agostino Walter BRUNO

Newcastle University

School of Engineering - Geotechnics and Structures

Devonshire Terrace

Drummond Building, Room 1.05

NE1 7RU, Newcastle upon Tyne

United Kingdom

e-mail: agostino.bruno@newcastle.ac.uk 


\section{ABSTRACT:}

This paper presents a bounding surface model to predict the hydromechanical behaviour of unsaturated soils under isotropic stress states. The model combines the hydraulic law of Gallipoli et al. (2015) with the mechanical law of Gallipoli and Bruno (2017). The hydraulic law relates the degree of saturation to the single variable scaled suction, which accounts for the effect of both suction and void ratio on the water retention behaviour of soils. The hydraulic law is made up of two closed-form equations, one for drying paths and one for wetting paths. Similarly, the mechanical law relates the void ratio to the single variable scaled stress, which accounts for the effect of both stress state and degree of saturation on the deformation of soils. The mechanical law is made up of two closed-form equations, one for loading paths and one for unloading paths. The proposed hydromechanical model is expressed in a finite form and has therefore the advantage of not requiring any approximate numerical integration. The model has been validated against four sets of laboratory data showing a good ability to predict the coupled behaviour of unsaturated soils (e.g. collapse-compression upon wetting) by means of a relatively small number of material parameters.

KEYWORDS: unsaturated soils; suction; capillarity; hydromechanical behaviour; bounding surface plasticity; constitutive modelling. 


\section{INTRODUCTION}

The prediction of the hydromechanical behaviour of soils is important for the design of geotechnical works from shallow foundations to retaining structures, from embankments to dams and slopes. In all these problems, the retention and deformation behaviour of the soil must be correctly predicted, which is only possible if accurate material laws are assumed.

Geotechnical modellers have traditionally formulated separate hydraulic and mechanical laws for predicting the retention and deformation behaviour of soils, respectively. Hydraulic models have been proposed by e.g. Brooks and Corey (1964), Van Genuchten (1980) and Fredlund and Xing (1994) while mechanical models have been proposed by e.g. Alonso et al. (1990), Wheeler and Sivakumar (1995) and Cui and Delage (1996). Experimental evidence demonstrates, however, that the retention behaviour influences the deformation while, vice-versa, the deformation influences the retention behaviour. Coupling hydraulic and mechanical laws in a single constitutive framework is therefore necessary for the accurate prediction of the soil response to external actions (e.g. Wheeler, 1996; Dangla et al., 1997; Gallipoli et al., 2003a; Gallipoli et al., 2003b; Sheng et al., 2004). The literature already offers a number of coupled hydromechanical frameworks, which are based on classic elastoplasticity (e.g. Vaunat et al., 2000; Wheeler et al., 2003; Tarantino and Tombolato, 2005). These models provide however only a limited description of hydromechanical hysteresis and introduce unrealistic discontinuities at the transition point between elastic and plastic states. To overcome these shortcomings, alternative approaches have been proposed such as, for example, hypoplastic models (e.g. Gudehus, 1995; Niemunis, 2003; Bauer et al., 2007; Mašín and Khalili, 2008; Fuentes and Triantafyllidis, 2013) and bounding surface models (Russell and Khalili, 2006; Khalili et al., 2008; Morvan et al., 2010; Zhou et al., 2015).

This paper presents a hydromechanical model for unsaturated soils subjected to isotropic stress states that is formulated within the broad framework of bounding surface plasticity. The model combines the hydraulic law by Gallipoli et al. (2015) with the mechanical law by Gallipoli and Bruno (2017) to predict the coupled 
variation of void ratio and degree of saturation due to changes of stress and suction. The hydraulic law predicts the hysteretic variation of degree of saturation as a function of a single independent variable, named the "scaled suction", which is equal to the suction scaled by a power function of void ratio. The hydraulic law consists of two equations corresponding to increasing and decreasing values of scaled suction, respectively. The mechanical law predicts the hysteretic variation of void ratio as a function of a single independent variable, named the "scaled stress", which is equal to the average skeleton stress (also known as Bishop's stress) scaled by a power function of degree of saturation. The mechanical law consists of two equations corresponding to increasing and decreasing values of scaled stress, respectively. Importantly, both hydraulic and mechanical laws are formulated as closed-form expressions of their respective constitutive variables and therefore do not require any approximate numerical integration.

The above hydraulic and mechanical laws have been coupled by means of an iterative procedure that solves simultaneously the two sets of equations. The resulting model requires a total of twelve material parameters, i.e. seven parameters for the retention law and five parameters for the mechanical law. Calibration of all parameters can be performed by fitting as little as a single experimental cycle of scaled suction or scaled stress.

The model has been validated against four distinct sets of laboratory data by Sivakumar (1993), Sharma (1998), Raveendiraraj (2009) and Garakani et al. (2015), which cover different types of soils from kaolin and bentonite clays to loess silt. Comparison with experimental data demonstrates the capability of the proposed model to capture typical features of the hydromechanical behaviour of unsaturated soils including the occurrence of either collapse-compression or swelling upon wetting. The proposed framework lays the basis for the development of a general constitutive law accounting for non-isotropic stress states.

\section{HYDROMECHANICAL MODEL}

This section recalls the main features of the hydraulic and mechanical laws followed by a description of the iterative coupling procedure. 


\section{Hydraulic law}

The hydraulic law, detailed in Gallipoli et al. (2015), describes the hysteretic variation of degree of saturation, $S_{r}$ caused by changes of suction, $s=u_{a}-u_{w}$ (where $u_{a}$ and $u_{w}$ are the pore air and water pressures, respectively) and void ratio, $e$. In particular, the variation of the degree of saturation is related to a single independent variable named the "scaled suction" $\bar{S}$ (Gallipoli et al., 2015), which is equal to the suction scaled by a power function of void ratio :

$$
\bar{s}=s e^{\frac{1}{\lambda_{s}}}
$$

where $\lambda_{s}$ is a material parameter.

Two main drying and wetting curves define the bounding hysteretic loop which delimits the region of admissible soil states in the plane of degree of saturation $S_{r}$ - scaled suction $\bar{s}$ (Figure 1 ). The mathematical expression of these two main curves is based on the van Genuchten (1980) equation as:

$$
S_{r}=\left(1+\left(\frac{\bar{s}}{\omega_{i}}\right)^{\frac{\lambda_{s}}{m_{i}}}\right)^{-m_{i}}
$$

where the parameter subscript $i$ is equal to either $d$ or $w$ depending on whether the equation describes the main drying or wetting curve. A total of five material parameters, i.e. $\lambda_{s}, \omega_{d}, m_{d}, \omega_{w}, m_{w}$, are therefore necessary to define the main hysteretic loop.

Figures $1 \mathrm{a}$ and $1 \mathrm{~b}$ show a schematic view of the two main curves in both the $\log S_{r}-\log \bar{s}$ and $S_{r}-\log \bar{s}$ planes, respectively. The parameter $\lambda_{s}$ coincides with the asymptotic slope of the two main curves when the scaled suction tends to infinity in the $\log S_{r}-\log \bar{s}$ plane. This slope must be identical for both curves to ensure the continuity of the stress path at the reversal point of drying-wetting cycles as shown by Gallipoli et al. (2015). The physical meaning of all model parameters, together with their range of variation, is discussed in Gallipoli et al. (2015). 

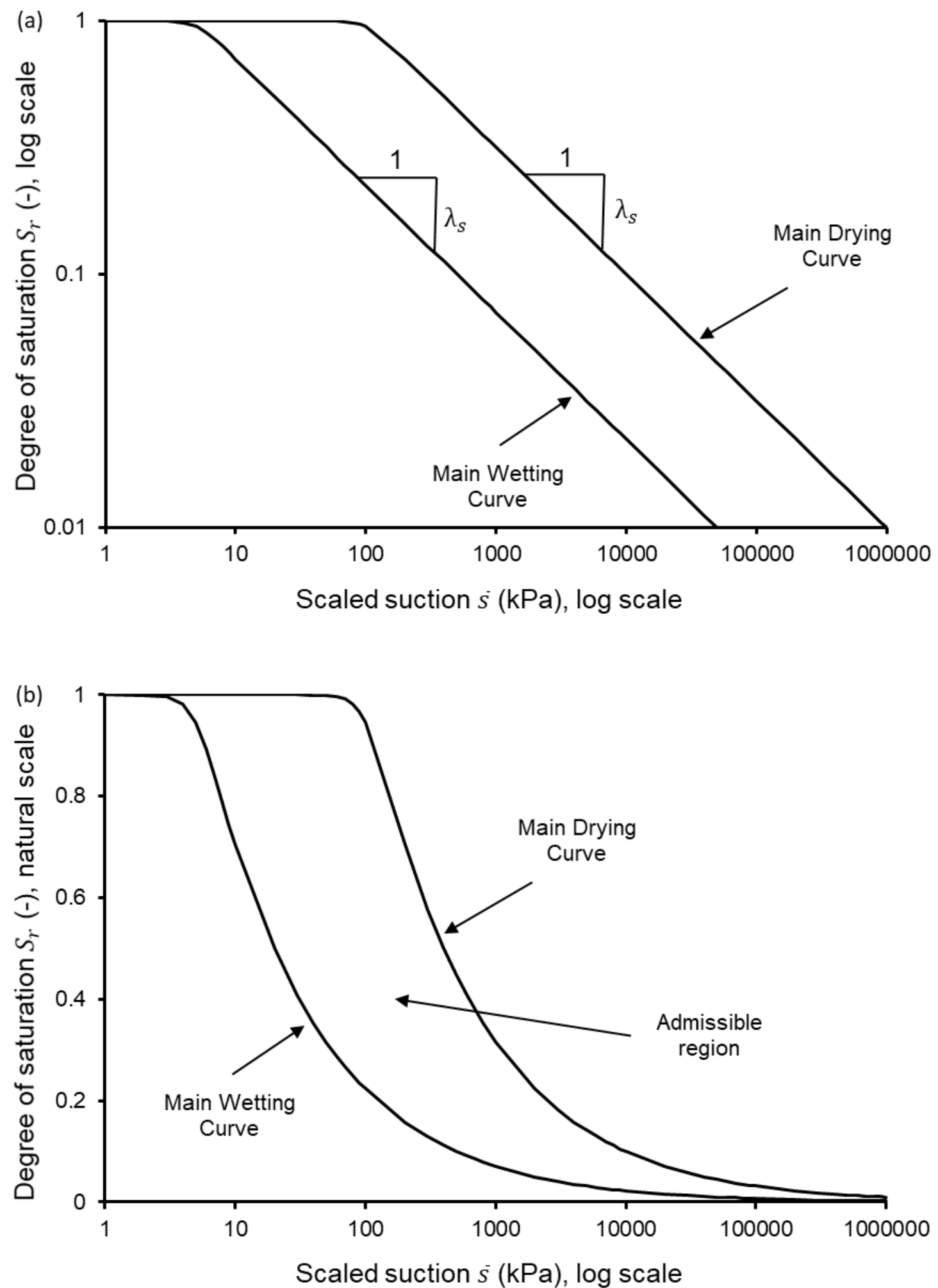

Figure 1. Main drying and main wetting curves in the $\log S_{r^{-}} \log \bar{s}(a)$ and $S_{r^{-}} \log \bar{s}(b)$ planes

Inside the region between the two main curves, drying and wetting paths are defined as soil paths characterized by a decrease and increase of degree of saturation, respectively. A key assumption in the 
work of Gallipoli et al. (2015) is that, as the soil state moves from one main curve to the other, the derivative of the degree of saturation with respect to the logarithm of the scaled suction (i.e. the slope of the drying or wetting path in the $S_{r}-\log \bar{s}$ plane) changes monotonically towards the derivative of the approached main curve. This ensures a smooth transition of the generic drying or wetting path inside the admissible region towards the corresponding main curve.

The derivative of the generic drying or wetting path can be integrated in a closed form (Gallipoli et al., 2015). This means that all drying curves are described by the same integral equation as:

$$
\left(S_{r}\right)_{d}=\left(1+\left(\frac{\bar{s}^{\beta_{d}}+C_{d}}{\omega_{d}^{\beta_{d}}}\right)^{\frac{\lambda_{s}}{\beta_{d} m_{d}}}\right)^{-m_{d}}
$$

where $C_{d}$ is the constant of integration and $\beta_{d}$ is an additional material parameter appearing in the derivative of the drying path (Gallipoli et al., 2015). Distinct drying curves are identified by different values of the constant of integration $C_{d}$, which is calculated by imposing a boundary condition at a chosen soil state, i.e. by substituting known values of degree of saturation $S_{\text {ro }}$ and scaled suction $\bar{s}_{o}$ inside Equation (3) as:

$$
C_{d}=\omega_{d}^{\beta_{d}}\left(S_{r_{o}}{ }^{-\frac{1}{m_{d}}}-1\right)^{\frac{\beta_{d} m_{d}}{\lambda_{s}}}-\bar{s}_{o} \beta_{d}
$$

Similarly, all wetting curves are described by the same integral equation as:

$$
\left(S_{r}\right)_{w}=\left(1+\left(\frac{\bar{s}^{\beta_{w}}}{\omega_{w}^{\beta_{w}}\left(1+C_{w} \bar{s}_{w}\right)}\right)^{\frac{\lambda_{s}}{\beta_{w} m_{w}}}\right)^{-m_{w}}
$$

where $C_{w}$ is the constant of integration and $\beta_{w}$ is an additional material parameter appearing in the derivative of the wetting paths (Gallipoli et al., 2015). The constant of integration $C_{w}$ is unique to each wetting curve and is calculated by substituting known values of degree of saturation $S_{\text {ro }}$ and scaled suction $\bar{s}_{O}$ inside Equation (5) as: 


$$
C_{w}=\frac{1}{\omega_{w}^{\beta_{w}}}\left(S_{r_{o}}{ }^{-\frac{1}{m_{w}}}-1\right)^{-\frac{\beta_{w} m_{w}}{\lambda_{s}}}-\frac{1}{\bar{s}_{o} \beta_{w}}
$$

In summary, the hydraulic law requires a total of seven parameters (i.e. $\lambda_{s}, \omega_{d}, m_{d}, \beta_{d}, \omega_{w}, m_{w}, \beta_{w}$ ) to predict a smooth hysteretic variation of degree of saturation that accounts for the effect of volumetric deformation on water retention. As mentioned, drying paths correspond to a decrease of degree of saturation while wetting paths correspond to an increase of degree of saturation which, according to Equations (3) and (5), correspond to an increase and a decrease of scaled suction, respectively. Consistent with the definition of scaled suction in Equation (1), a drying path may therefore be produced not only by an increase of suction but also by an increase of void ratio. Similarly, a wetting path may be produced not only by a decrease of suction but also by a decrease of void ratio. This is consistent with experimental evidence indicating that an increase of pore volume at constant suction causes a decrease of degree of saturation while a reduction of pore volume at constant suction causes an increase of degree of saturation.

\section{Mechanical law}

The mechanical law, detailed in Gallipoli and Bruno (2017), simulates the hysteretic variation of void ratio as a function of the mean average skeleton stress, $p^{\prime}=p-u_{a}+S_{r} s$ (where $p$ is the mean total stress) and degree of saturation, $S_{r}$. The average skeleton stress reduces, under saturated condition, to Terzaghi's effective stress, which is the reason why the same notation has here been used.

As described in Gallipoli and Bruno (2017), the mechanical law originates from the following definition of capillary bonding function for virgin soil states:

$$
\frac{e}{e_{S}}=S_{r}^{-\lambda_{r}}
$$

or, alternatively, in the $\log \frac{e}{e_{s}}-\log S_{r}$ plane:

$$
\log \frac{e}{e_{s}}=-\lambda_{r} \log S_{r}
$$


where $\frac{e}{e_{S}}$ is the fraction between the unsaturated void ratio $e$ and the saturated void ratio $e_{s}$ at the same value of mean average skeleton stress while $\lambda_{r}$ is a model parameter. The fraction $\frac{e}{e_{s}}$ is always bigger than one because, at any given value of the mean average skeleton stress, the void ratio under unsaturated conditions is larger than the void ratio under saturated conditions due to the stabilizing effect of capillary menisci at inter-particle contacts. Therefore, the fraction between the unsaturated and saturated values of void ratio constitutes a measure of capillary bonding and reduces with increasing saturation levels according to a negative power of the degree of saturation as indicated by Equation (7a). Figure 2 shows a representation of the capillary bonding function in the $\log \frac{e}{e_{s}}-\log S_{r}$ plane where the parameter $\lambda_{r}$ coincides with the negative slope of the resulting linear relationship.

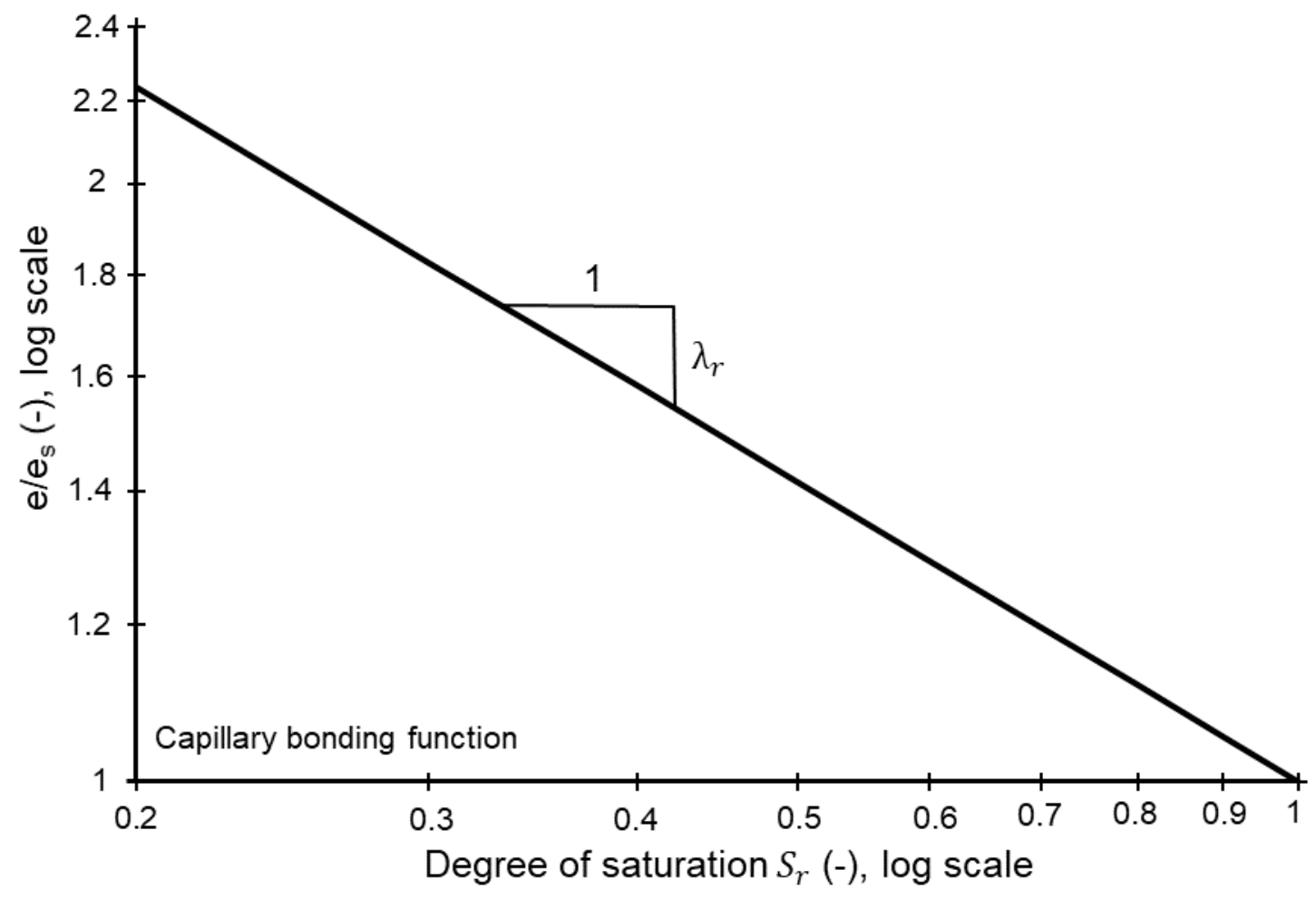

Figure 2. Capillary bonding function in the $\log \frac{e}{e_{s}}-\log S_{r}$ plane

In Equations (7a) and (7b), the saturated void ratio $e_{s}$ is obtained from the following double logarithmic expression of the saturated normal compression line: 


$$
\log e_{s}=-\lambda_{p} \log \frac{p^{\prime}}{p_{r e f}^{\prime}}
$$

where the parameters $\lambda_{p}$ and $p_{r e f}^{\prime}$ are respectively the slope and reference stress (corresponding to a reference void ratio with a numerical value of one) of the saturated normal compression line. Note that, due to the saturated state of the soil, the mean average skeleton stress $p^{\prime}$ in Equation (8) coincides with Terzaghi's effective stress.

By combining Equation (7a) or (7b) with Equation (8), one obtains the following expression of the unified normal compression line, which predicts the variation of void ratio during both saturated and unsaturated virgin loading:

$$
\log e=-\lambda_{p} \log \frac{p^{\prime} S_{r}^{\frac{\lambda_{r}}{\lambda_{p}}}}{p_{r e f}^{\prime}}
$$

In Equation (9), the product between the mean average skeleton stress $p^{\prime}$ and the power function of degree of saturation $S_{r}^{\frac{\lambda_{r}}{\lambda p}}$ defines a new constitutive variable named the mean "scaled stress" $\bar{p}$ as:

$$
\bar{p}=p^{\prime} S_{r}^{\frac{\lambda_{r}}{\lambda_{p}}}
$$

The name of this constitutive variable derives from its mathematical form, which is equal to the mean average skeleton stress scaled by a power function of the degree of saturation.

The unified normal compression line of Equation (9) is therefore rewritten in terms of the mean scaled stress $\bar{p}$ as:

$$
\log e=-\lambda_{p} \log \frac{\bar{p}}{\overline{\bar{p}_{\text {ref }}}}
$$


Note that, in Equation (11), the reference average skeleton stress $p_{r e f}^{\prime}$ has been replaced by the reference scaled stress $\bar{p}_{\text {ref }}$ because under saturated conditions $p^{\prime}=\bar{p}$ according to Equation (10). A total of three parameters, i.e. $\lambda_{r}, \lambda_{p}, \bar{p}_{\text {ref }}$, are therefore required to define the unified normal compression line for saturated and unsaturated soils. This is only one parameter more, i.e. $\lambda_{r}$, than the normal compression line for saturated soils, which is defined by the two parameters $\lambda_{p}$ and $\bar{p}_{r e f}$.

Similar to the hydraulic law, the unified normal compression line delimits a region of admissible (overconsolidated) soil states in the $\log e-\log \bar{p}$ plane. Inside this region, loading and unloading paths correspond to increasing and decreasing values of mean scaled stress, respectively. Due to the definition of the mean scaled stress (Equation 10), a loading path may be produced not only by an increase of mean average skeleton stress but also by an increase of degree of saturation. Similarly, an unloading path may be produced not only by a decrease of mean average skeleton stress but also by a decrease of degree of saturation. Thanks to this feature, the model can predict either swelling or collapse-compression upon suction reduction depending on the relative changes of mean average skeleton stress and degree of saturation as discussed later in the paper.

In the work of Gallipoli and Bruno (2017), it is assumed that, as the soil state approaches the unified normal compression line during loading, the derivative of the logarithm of void ratio with respect to the logarithm of scaled stress (i.e. the slope of the loading path in the $\log e-\log \bar{p}$ plane) changes monotonically towards the derivative of the unified normal compression line. This ensures a smooth transition of all loading paths towards the normal compression line. Interestingly, the mathematical expression of this derivative can be integrated in a closed form, which implies that the all loading curves are described by the following integral equation:

$$
e=\left(\left(\frac{\bar{p}}{\bar{p}_{\text {ref }}}\right)^{\gamma}+C_{l}\right)^{-\frac{\lambda_{p}}{\gamma}}
$$

where $C_{l}$ is the constant of integration and $\gamma$ is an additional material parameter in the expression of the derivative of the loading paths (Gallipoli and Bruno, 2017). The constant of integration $C_{l}$ is unique for each 
loading curve and is obtained by imposing a boundary condition, i.e. by substituting a known pair of values of void ratio $e_{o}$ and scaled stress $\bar{p}_{o}$ in Equation (12). This substitution leads to the following explicit expression of $C_{l}$ :

$$
C_{l}=e_{o}^{-\frac{\gamma}{\lambda_{p}}}-\left(\frac{\bar{p}_{o}}{\bar{p}_{\text {ref }}}\right)^{\gamma}
$$

During unloading, it is instead assumed that the derivative of the logarithm of void ratio with respect to the logarithm of scaled stress is constant and that unloading paths are therefore linear in the $\log e-\log \bar{p}$ plane with slope equal to the swelling coefficient, $\kappa$. This constant derivative is easily integrated in a closed form, which means that all unloading curves are described by the following integral equation:

$$
e=\frac{C_{u}}{\bar{p}^{\kappa}}
$$

where $C_{u}$ is the constant of integration. The value of $C_{u}$ identifies each distinct unloading curve and is calculated by substituting known values of void ratio $e_{o}$ and scaled stress $\bar{p}_{o}$ inside Equation (14). This leads to the following explicit expression of $C_{u}$ :

$$
C_{u}=e_{o} \bar{p}_{o}{ }^{k}
$$

In summary, the mechanical law requires a total of five parameters (i.e. $\lambda_{p}, \lambda_{r}, \bar{p}_{r e f}, \gamma, \kappa$ ) to predict a smooth hysteretic variation of void ratio that accounts for the effect of capillary bonding on deformation.

Together with the seven parameters of the hydraulic law, a total of twelve parameters is therefore required to describe the smooth, hysteretic hydromechanical behaviour of the soil under isotropic stress states.

\section{Iterative coupling procedure}

The previous hydraulic and mechanical laws have been coupled in this work to calculate the variation of degree of saturation $S_{r}$ and void ratio $e$ along a generic soil path defined in terms of mean net stress $p^{n e t}=p-u_{a}$ and suction $s=u_{a}-u_{w}$ (mean net stress and suction are the two soil variables that are typically controlled during laboratory tests). The simulation of the soil path progresses in steps, wherein the 
non-linear hydraulic and mechanical equations are simultaneously solved by means of an iterative process. Because these equations are provided in a closed form, the accuracy of the simulation is independent of the chosen step size.

In each step, the iterative process starts from a trial value of degree of saturation, which may be taken to coincide with the degree of saturation calculated at the end of the previous step. This trial degree of saturation is introduced in Equation (10) to obtain a trial scaled stress, which is then substituted in either Equation (12) or (14) to calculate a trial value of void ratio. The choice of Equation (12) or (14) depends on whether the soil is assumed to move along a loading or an unloading path (the correctness of this assumption will be checked at the end of the iteration). The trial void ratio is subsequently introduced in either Equation (3) or (5), depending on whether the soil is assumed to move along a drying or wetting path (the correctness of this assumption will be checked at the end of the iteration), to calculate a new value of degree of saturation. This newly calculated value of degree of saturation is then used to compute new values of scaled stress, void ratio and, finally, scaled suction.

The correctness of the previous assumptions of loading/unloading and drying/wetting path is now checked by comparing the current values of scaled stress and scaled suction with those calculated at the end of the previous step. If one of these two assumptions is false, the incorrect assumption is changed and the iteration is repeated with the new equation. Instead, if both assumptions are true, the algorithm moves to the next iteration where the current degree of saturation is taken as the new trial value.

It may, in principle, be possible that the new assumption also turns out to be incorrect when checked and that the algorithm then flips from one equation to the other without advancing. This behaviour has however never been observed in practice and is unlikely to happen due to the similar mathematical form of the drying and wetting (or loading and unloading) equations, whose derivatives have the same sign. This means that the computed changes of degree of saturation (or void ratio) have also the same sign regardless of which of the two equations is employed. 
Iterations are repeated $\mathrm{n}$ times until the values of degree of saturation and void ratio calculated in the $\mathrm{n}^{\text {th }}$ iteration, i.e. $S_{r, n}$ and $e_{n}$, differ by less than $0.1 \%$ from the corresponding values of the $\mathrm{n}-1^{\text {th }}$ iteration, i.e. $S_{r, n-1}$ and $e_{n-1}$. This condition is mathematically imposed by the following two inequalities:

$$
\begin{aligned}
& \left|\frac{S_{r, n}-S_{r, n-1}}{S_{r, n-1}}\right| \leq 0.001 \\
& \left|\frac{e_{n}-e_{n-1}}{e_{n-1}}\right| \leq 0.001
\end{aligned}
$$

If Equations (16a) and (16b) are simultaneously satisfied, the suction and mean net stress are incremented and the algorithm moves to the next step. Generally, a maximum of five iterations is required to satisfy the convergence criteria of Equations (16a) and (16b) but the number of iterations is reduced if a tolerance higher than 0.001 is assumed.

The initial values of the constants of integration in Equations (3), (5), (12) and (14) are calculated by imposing the coincidence between simulated and experimental curves at the beginning of the test. If the soil path reverts from drying to wetting (and vice versa) or from loading to unloading (and vice versa) during the simulation, new values of the constants of integrations are calculated by imposing the continuity of the simulated curve at the reversal point.

The above algorithm has been implemented in standard spreadsheet software to calibrate and subsequently validate the proposed coupled model against four experimental data sets by Sivakumar (1993) on kaolin clay, Sharma (1998) on kaolin/bentonite clay, Raveendiraraj (2009) on kaolin clay and Garakani et al. (2015) on loess silt. The calibration and validation of the proposed model are presented in the following sections.

\section{MODEL CALIBRATION}

\section{Calibration of the hydraulic law}


The seven parameters of the hydraulic law, i.e. $\lambda_{s}, \omega_{d}, \beta_{d}, m_{d}, \omega_{w}, \beta_{w}$ and $m_{w}$, have been calibrated by multi-variable least-square fitting of Equations (3) and (5) to experimental drying and wetting paths, respectively (i.e. paths corresponding to a increase and an decrease of scaled suction). During calibration, the constant of integration of the first drying or wetting path (i.e. $C_{d}$ or $C_{w}$ ) has been treated as an additional fitting parameter while the constants of integration of the subsequent drying or wetting paths have been calculated by imposing the continuity of the simulated curve at the reversal point (Gallipoli et al., 2015).

For the data sets by Raveendiraraj (2009) and Sharma (1998), the hydraulic model has been calibrated on the basis of a single test. In the former case, the test consisted of a suction cycle from $300 \mathrm{kPa}$ to $10 \mathrm{kPa}$ and back to $300 \mathrm{kPa}$ under a constant mean net stress of $10 \mathrm{kPa}$ (Figure 3). In the latter case, the test consisted of a mean net stress cycle from $10 \mathrm{kPa}$ to $200 \mathrm{kPa}$ and back to $20 \mathrm{kPa}$ under a constant suction of $100 \mathrm{kPa}$ (Figure 4). Due to the dependency of the scaled suction on both suction and void ratio, a scaled suction cycle can in fact be generated by both a suction cycle and a mean net stress cycle.

The data sets by Sivakumar (1993) and Garakani et al. (2015) contain only tests with decreasing values of scaled suction, which means that only the wetting parameters $\lambda_{s}, \omega_{w}, \beta_{w}$ and $m_{w}$ could be calibrated in these two cases. In the former case, the parameters have been calibrated on the basis of a single test consisting of an increase of mean net stress from $50 \mathrm{kPa}$ to $300 \mathrm{kPa}$ under a constant suction of $200 \mathrm{kPa}$ (Figure 5). In the latter case, the parameters have been calibrated by simultaneous fitting of two tests consisting of a decrease of suction from $750 \mathrm{kPa}$ to $1 \mathrm{kPa}$ under two distinct levels of mean net stresses of $50 \mathrm{kPa}$ (Figure 6a) and $200 \mathrm{kPa}$ (Figure 6b), respectively.

The simulated curves have been calculated by substituting inside the scaled suction expression of Equation (2) the experimental values of void ratio instead of the calculated ones. This is preferable during calibration to avoid that any potentially incorrect prediction of void ratio by the mechanical law could influence the selection of hydraulic parameters. Later, during model validation, degree of saturation and void ratio will instead be calculated in a fully coupled way by means of the simultaneous solution of the hydraulic and 
mechanical laws as previously described. Note that the apparently discontinuous slope of the curves shown in Figures $6 \mathrm{a}$ and $6 \mathrm{~b}$ is due to the coarseness of the experimental points, and corresponding simulated values, which are joined by straight lines.

Figures 3 to 6 show a good agreement between experimental and simulated curves for all data sets, which confirms the ability of the hydraulic law to predict the soil water retention behaviour along different paths.

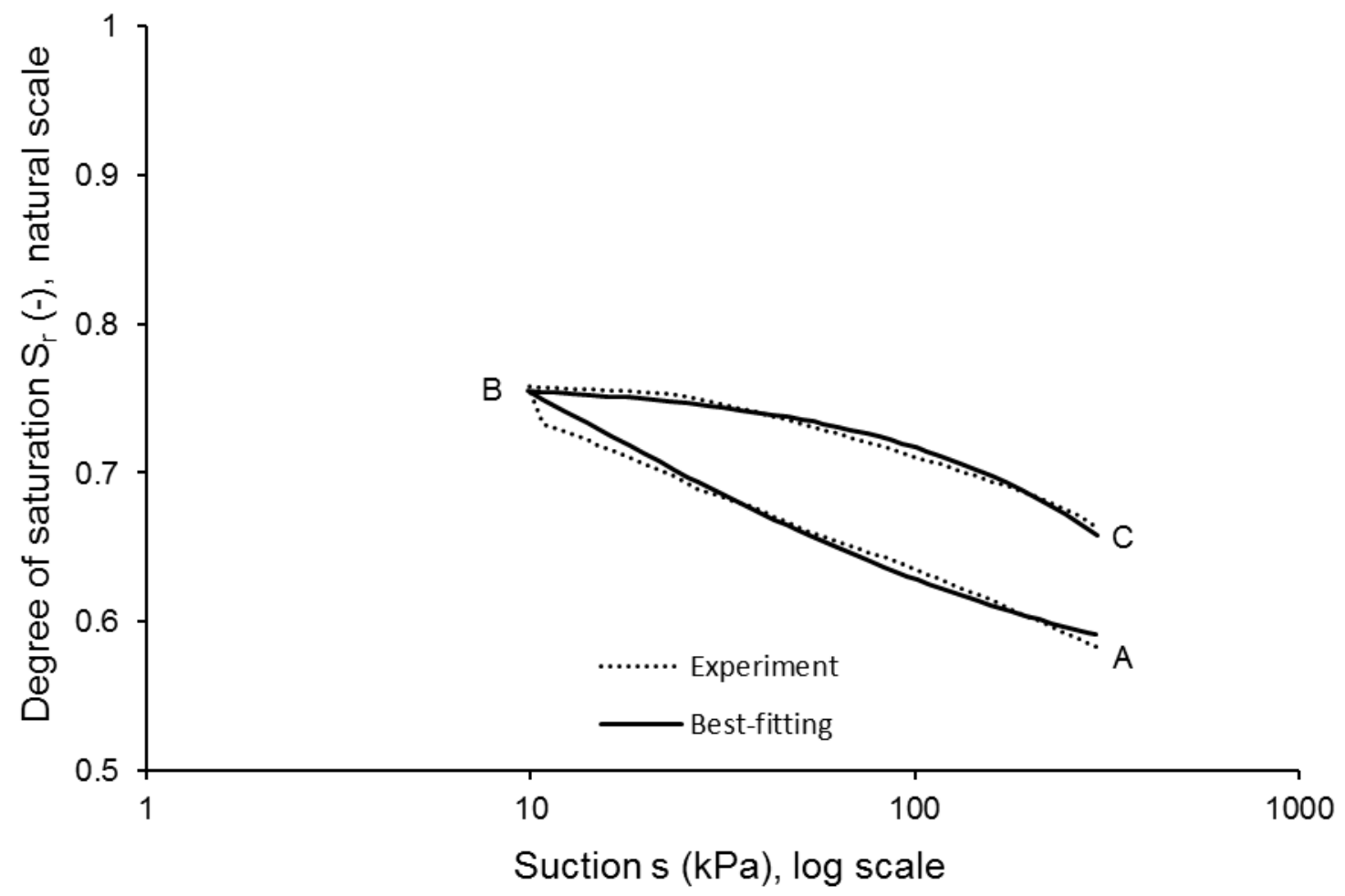

Figure 3. Hydraulic calibration by best-fitting of suction cycle at constant mean net stress of $10 \mathrm{kPa}$ on compacted kaolin (experimental data from Raveendiraraj, 2009) 


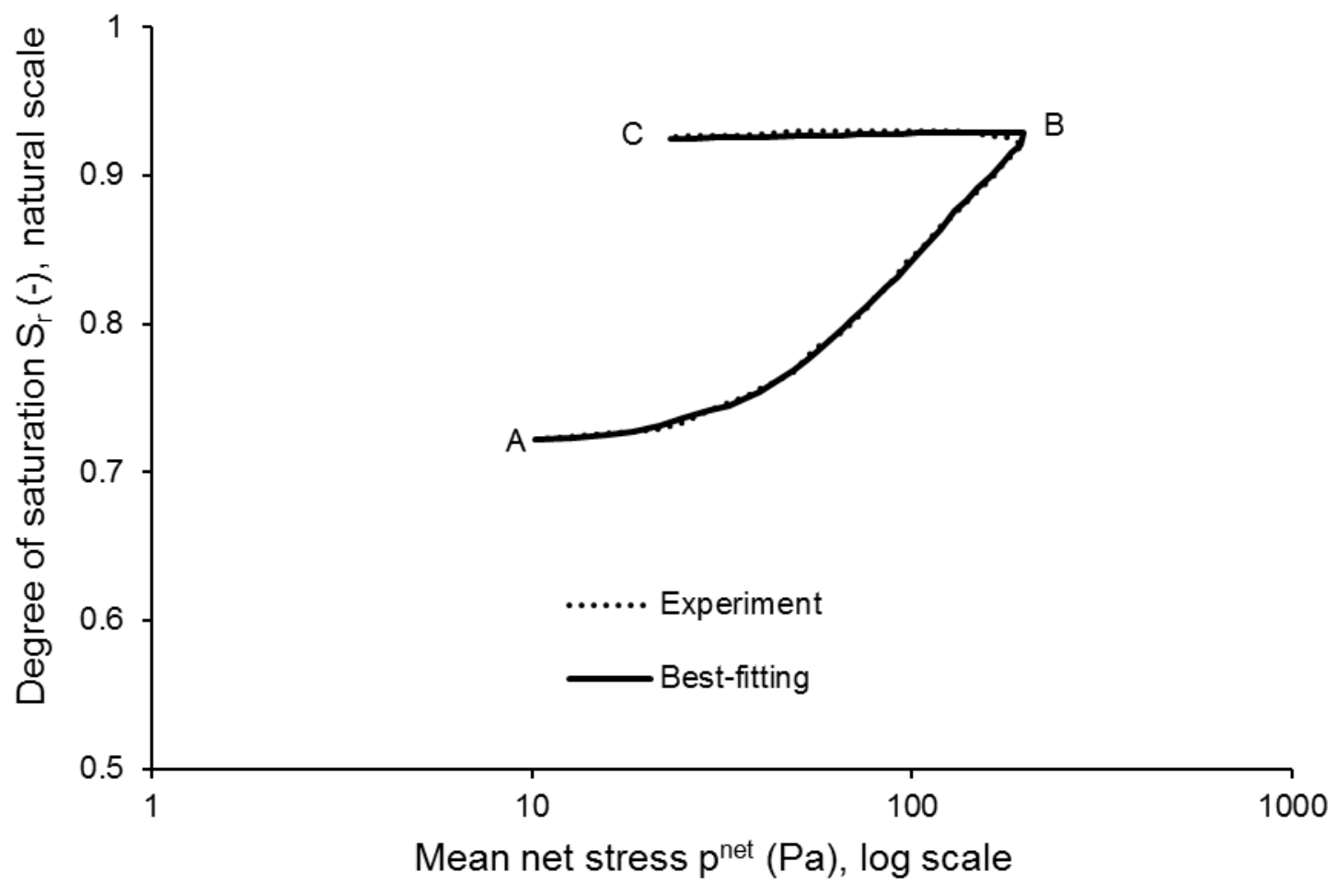

Figure 4. Hydraulic calibration by best-fitting of mean net stress cycle at constant suction of $100 \mathrm{kPa}$ on compacted kaolin/bentonite mix (experimental data from Sharma, 1998)

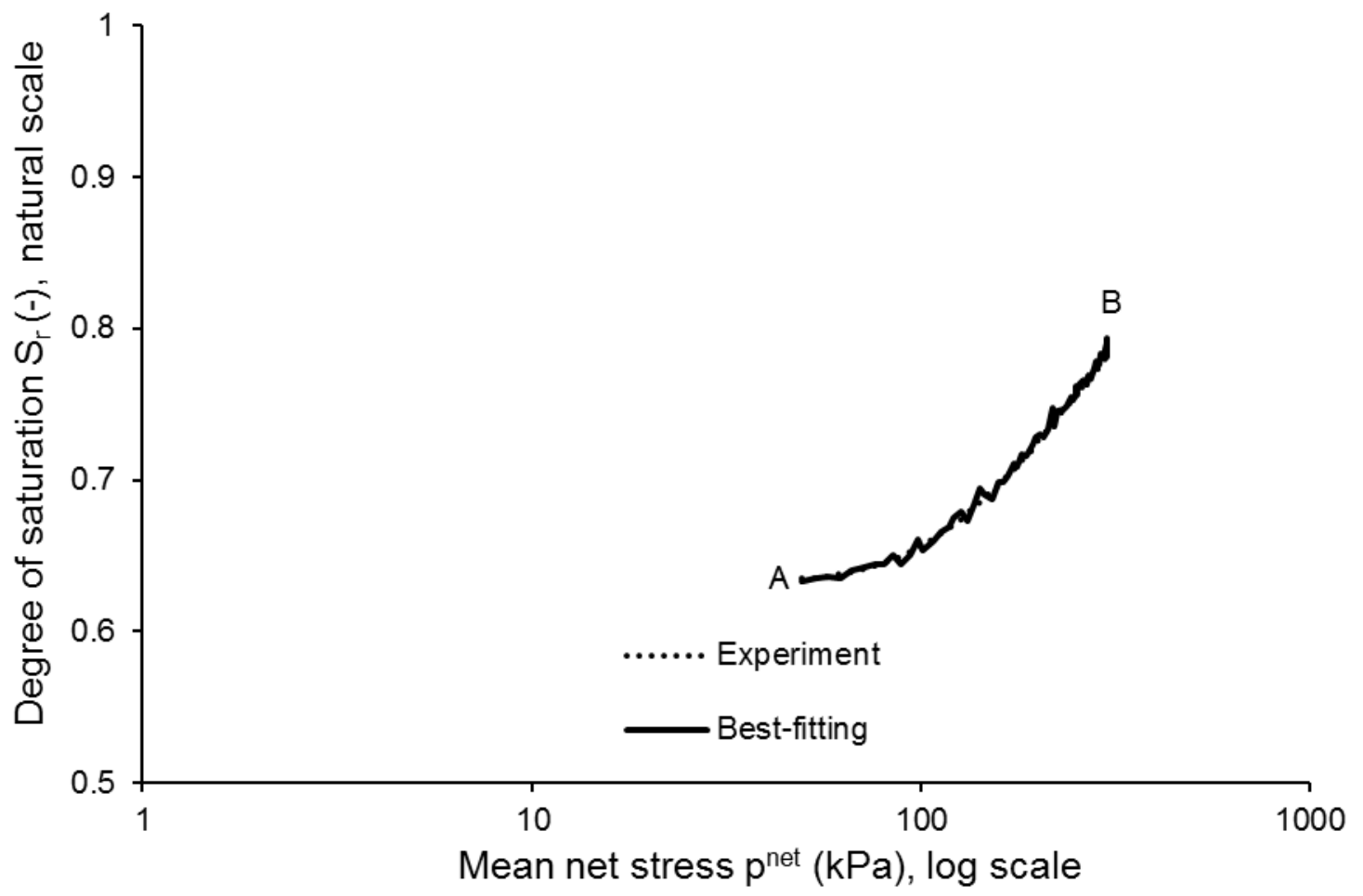

Figure 5. Hydraulic calibration by best-fitting of mean net stress increase at constant suction of $200 \mathrm{kPa}$ on compacted kaolin (experimental data from Sivakumar, 1993) 

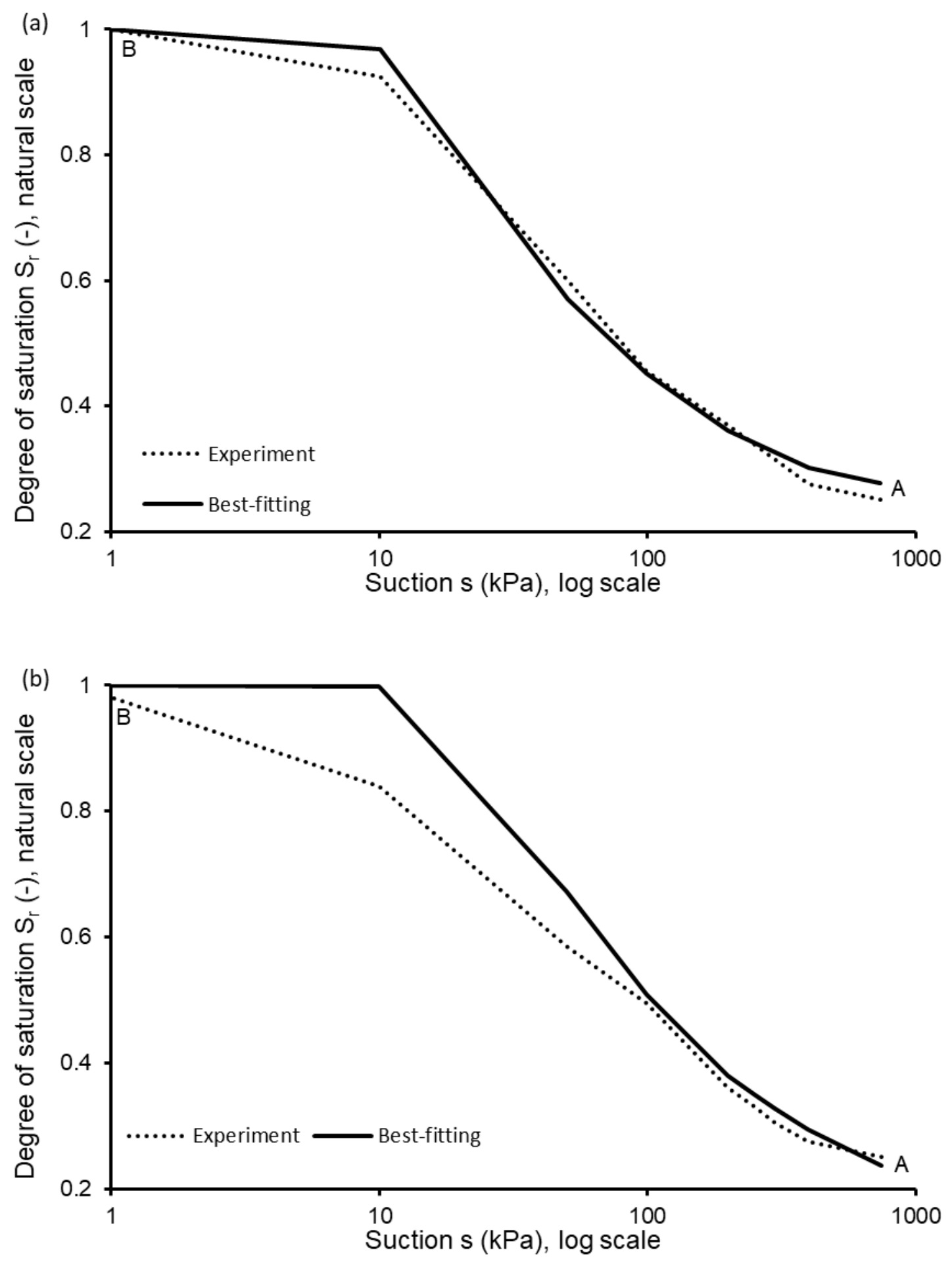

Figure 6. Hydraulic calibration by best-fitting of suction decrease at constant mean net stresses of $50 \mathrm{kPa}$ (6a) and $200 \mathrm{kPa}(6 \mathrm{~b})$ on undisturbed loess silt (experimental data from Garakani et al., 2015)

\section{Calibration of the mechanical law}


Gallipoli and Bruno (2017) already calibrated the mechanical parameters, i.e. $\lambda_{p}, \bar{p}_{r e f}, \lambda_{r}, \gamma$ and $k$, for the data sets of Sivakumar (1993), Sharma (1998) and Raveendiraraj (2009). This section therefore only calibrates the mechanical parameters for the data set of Garakani et al. (2015).

Likewise the hydraulic case, calibration could have been performed by multi-variable least-square fitting of Equations (12) and (14) to experimental loading and unloading paths, respectively (i.e. paths corresponding to an increase and decrease of scaled stress). Nevertheless, a different strategy has been adopted similar to the approach followed by Gallipoli and Bruno (2017) for the data sets by Sivakumar (1993), Sharma (1998) and Raveendiraraj (2009). This alternative strategy relies on the interpretation of the physical meaning of each parameter as explained later.

The parameters $\lambda_{p}$ and $\bar{p}_{\text {ref }}$ define the slope and intercept of the unified normal compression line (Equation 11) and have therefore been calibrated against isotropic virgin compression tests on saturated samples (Figure 7). In Figure 7, the data points at low levels of mean net stress correspond to overconsolidated soil states and have therefore been disregarded in the definition of the unified normal compression line.

The parameter $\lambda_{r}$ defines instead the slope of the capillary bonding function in the $\log \frac{e}{e_{s}}-\log S_{r}$ plane and has been calibrated by fitting Equation (7b) to virgin isotropic compression data (Figure 8 ) as discussed in Gallipoli and Bruno (2017).

Finally, the parameter $\gamma$ has been calibrated by means of simultaneous least-square fitting of Equation (12) to five different isotropic loading tests on overconsolidated samples where the mean net stress increasesfrom $1 \mathrm{kPa}$ to $300 \mathrm{kPa}$ under constant suction of 50,100, 200, 300 and $400 \mathrm{kPa}$, respectively. In the interest of brevity, only the fit for the loading path at the intermediate suction of $200 \mathrm{kPa}$ is shown in Figure 9. Unfortunately, the data by Garakani et al. (2015) do not include any unloading path, which means that the swelling parameter $k$ could not be calibrated. 


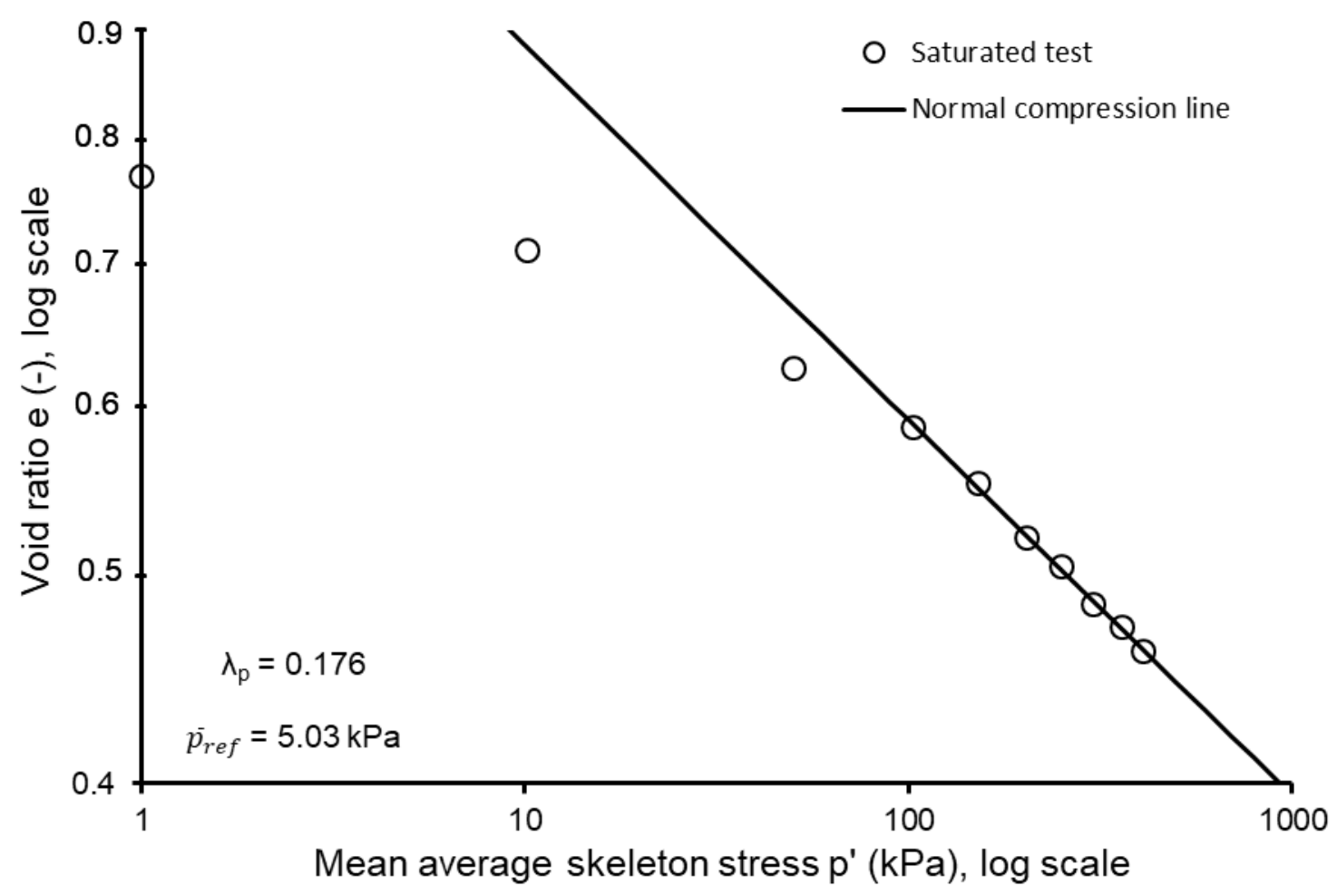

Figure 7. Calibration of parameters $\lambda_{p}$ and $\bar{p}_{\text {ref }}$ by best-fitting of saturated normal compression data for undisturbed loess silt (experimental data from Garakani et al., 2015)

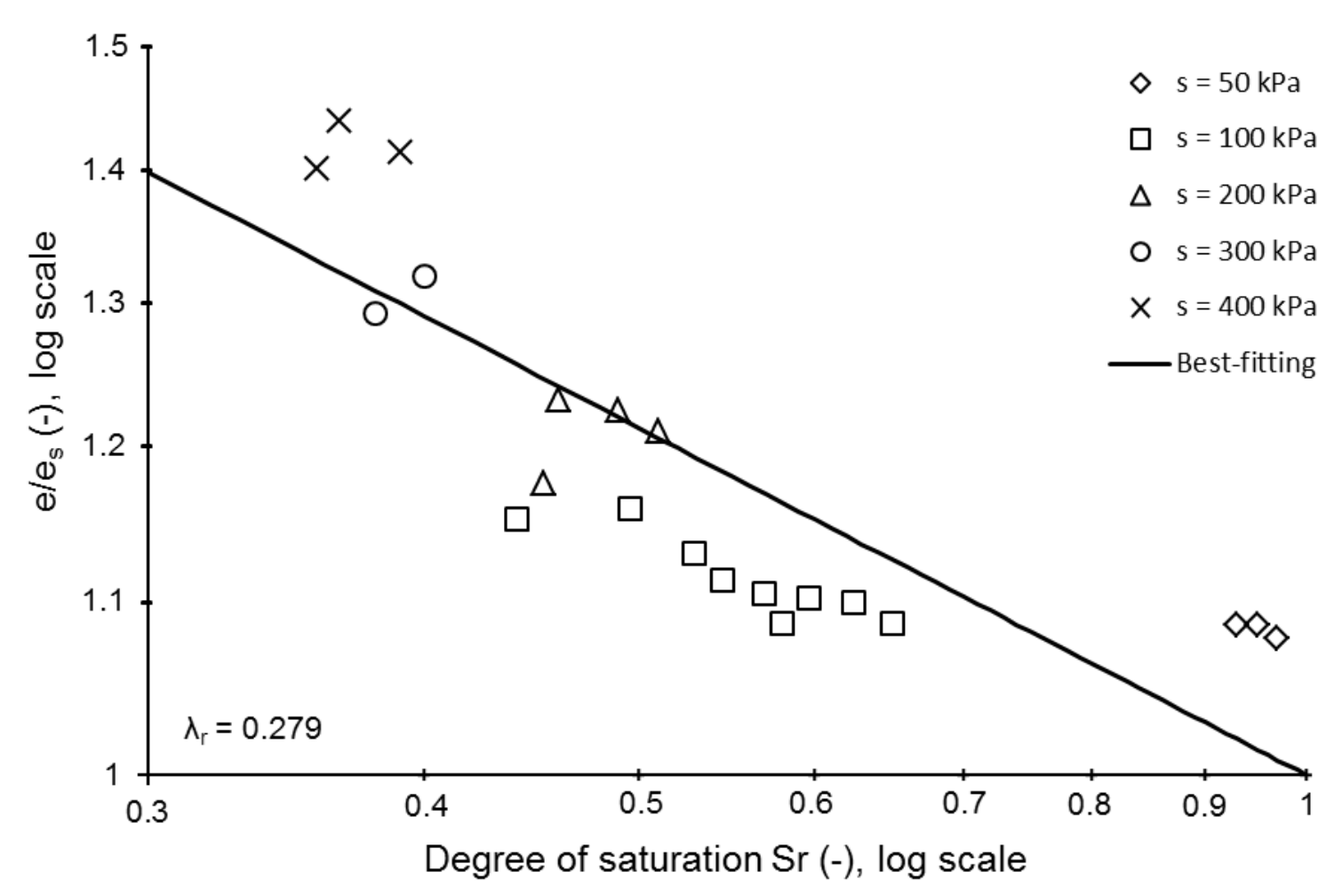

Figure 8. Calibration of parameter $\lambda_{r}$ by best-fitting of capillary bonding function to unsaturated and saturated normal compression data for undisturbed loess silt (experimental data from Garakani et al., 2015) 


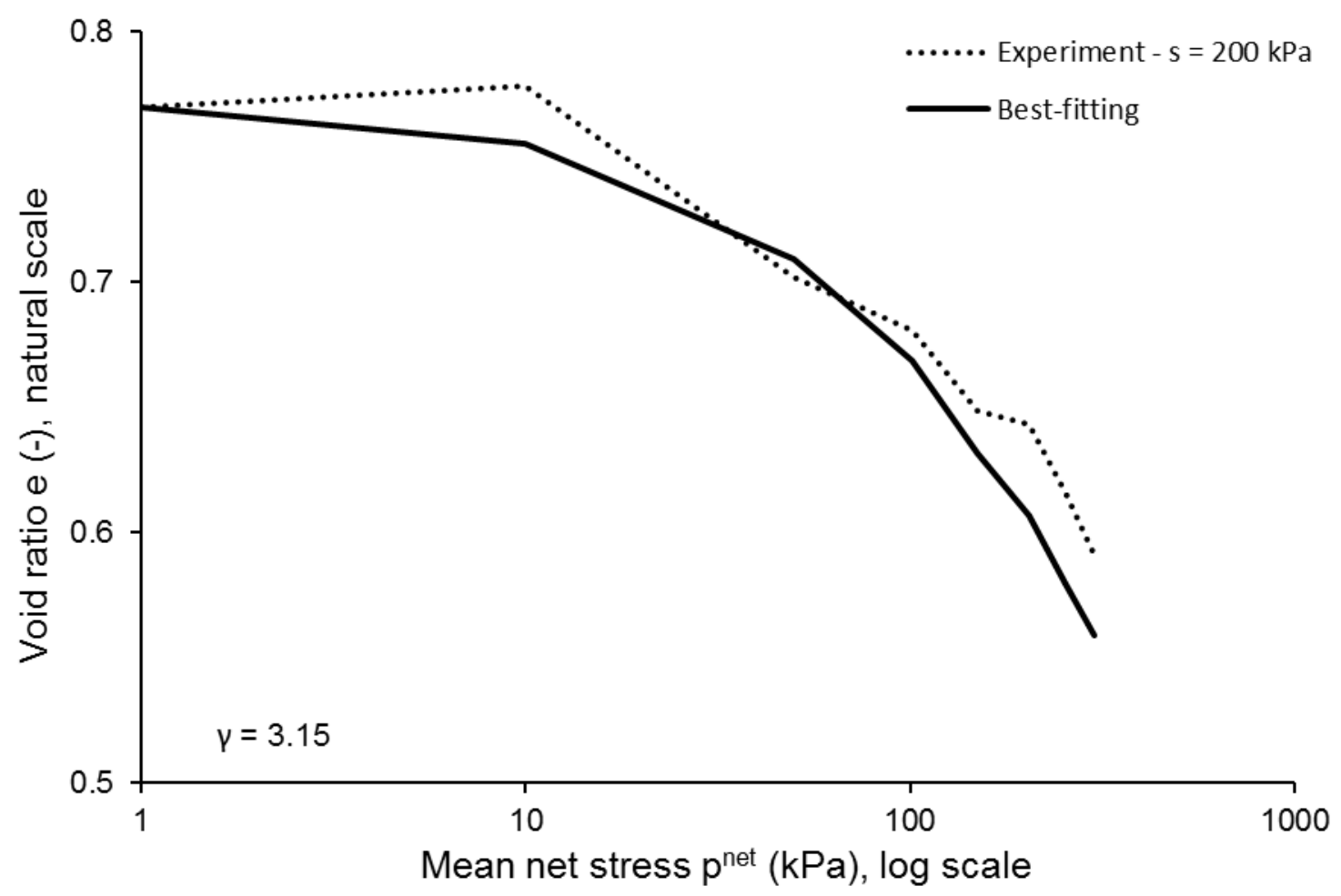

Figure 9. Calibration of parameter $\gamma$ by best-fitting of mean net stress increase at constant suction of 200 kPa on undisturbed loess silt (experimental data from Garakani et al., 2015)

Similar to the calibration of the hydraulic law, simulations have been calculated by substituting inside the scaled stress expression of Equation (10) the experimental values of degree of saturation instead of the calculated ones. This is preferable during calibration to avoid that any potentially incorrect prediction of degree of saturation by the hydraulic law could influence the selection of the mechanical parameters.

Table 1 lists all parameter values of the hydraulic and mechanical laws for the four experimental data sets considered in the present work. Note that the parameters of the mechanical law for the data sets by Sivakumar (1993), Sharma (1998) and Raveendiraraj (2009) are identical to those presented in Gallipoli and Bruno (2017).

Table 1. Values of model parameters

\begin{tabular}{|c|c|c|c|c|c|}
\hline & & $\begin{array}{c}\text { Raveendiraraj } \\
\text { (2009) }\end{array}$ & $\begin{array}{l}\text { Sharma } \\
\text { (1998) }\end{array}$ & $\begin{array}{l}\text { Sivakumar } \\
\text { (1993) }\end{array}$ & $\begin{array}{c}\text { Garakani et al. } \\
\text { (2015) }\end{array}$ \\
\hline \multirow{3}{*}{$\begin{array}{c}\text { Hydraulic } \\
\text { law }\end{array}$} & $\lambda_{s}$ & 0.968 & 0.145 & 1.01 & 0.329 \\
\hline & $\omega_{w}$ & $2186 \mathrm{kPa}$ & $32.8 \mathrm{kPa}$ & $146 \mathrm{kPa}$ & $3.06 \mathrm{kPa}$ \\
\hline & $m_{W}$ & 2.51 & 0.052 & 0.026 & 0.075 \\
\hline
\end{tabular}




\begin{tabular}{cccccc}
\hline & $\beta_{W}$ & 0.698 & 0.169 & 0.130 & 2.21 \\
& $\omega_{d}$ & $2186 \mathrm{kPa}$ & $600 \mathrm{kPa}$ & - & - \\
& $m_{d}$ & 0.150 & 0.052 & - & - \\
\hline$\beta_{d}$ & 0.870 & 0.839 & - & 0.279 \\
Mechanical & $\lambda_{r}$ & 0.519 & 0.521 & 0.490 & 0.178 \\
law & $\lambda_{p}$ & 0.124 & 0.160 & 0.125 & $5.03 \mathrm{kPa}$ \\
& $\bar{p}_{r e f}$ & $83 \mathrm{kPa}$ & $200 \mathrm{kPa}$ & $164 \mathrm{kPa}$ & 3.15 \\
& $\gamma$ & 4.00 & 5.42 & 7.15 & - \\
\hline
\end{tabular}

\section{MODEL VALIDATION}

The predictive capability of the proposed hydromechanical model has been validated against additional experimental data not used during calibration. Model predictions have been calculated by coupling the hydraulic and mechanical laws via the previously described iterative algorithm. The values of degree of saturation predicted by the hydraulic law have been used to calculate the scaled stress $\bar{p}$ in the mechanical law and, vice versa, the values of void ratio predicted by the mechanical law have been used to calculate the scaled suction $\bar{s}$ in the hydraulic law.

For the data by Raveendiraraj (2009), the model has been validated against a drying-wetting cycle at a constant mean net stress of $10 \mathrm{kPa}$, where the suction firstly increases from 30 to $300 \mathrm{kPa}$, then reduces to $40 \mathrm{kPa}$ and finally increases again to $200 \mathrm{kPa}$. Inspection of Figures 10a and 10b indicates a good agreement between predictions and experiments for both the mechanical and hydraulic behaviour of the soil.

For the data by Sharma (1998), the model has been validated against a loading-unloading cycle at a constant suction of $200 \mathrm{kPa}$, where the mean net stress is increased from 10 to $100 \mathrm{kPa}$, then reduced to 40 $\mathrm{kPa}$ and increased again to $250 \mathrm{kPa}$ before being finally reduced to $110 \mathrm{kPa}$. The results of this simulation are shown in Figures 11a and 11b, which confirm the good capability of the model to predict both void ratio and degree of saturation.

For the data by Sivakumar (1993), no cycle of mean net stress or suction is available and model predictions have therefore been validated against a loading path where the mean net stress is increased from 50 to 
$150 \mathrm{kPa}$ at a constant suction of $300 \mathrm{kPa}$. Figures $12 \mathrm{a}$ and $12 \mathrm{~b}$ show again an accurate prediction of the hydromechanical behaviour of the soil.

Finally, the ability of the proposed model to predict collapse-compression upon a reduction of suction has been validated against a wetting path on loess silt from Garakani et al. (2015) where suction is reduced from $750 \mathrm{kPa}$ to $1 \mathrm{kPa}$ at a constant mean net stress of $400 \mathrm{kPa}$. Figures $13 \mathrm{a}$ and $13 \mathrm{~b}$ confirm that the proposed model correctly predicts the collapse-compression of the soil during saturation. As discussed by Gallipoli and Bruno (2017), the ability of the model to predict either swelling (branch BC in Figure 10a) or collapse (branch $A B$ in Figure 13a) during a decrease of suction originates from the definition of the scaled stress variable. This variable is defined in Equation (10) as the product of two terms, i.e. the mean average skeleton stress $p^{\prime}=p-u_{a}+S_{r} s$ and the bonding factor $S_{r}^{\frac{\lambda_{r}}{\lambda_{p}}}$, which evolve in opposite directions as suction decreases and degree of saturation increases. This means that, depending on which of these two terms prevails, a decrease of suction could induce either a decrease or an increase of scaled stress, which would respectively produce swelling or collapse-compression.

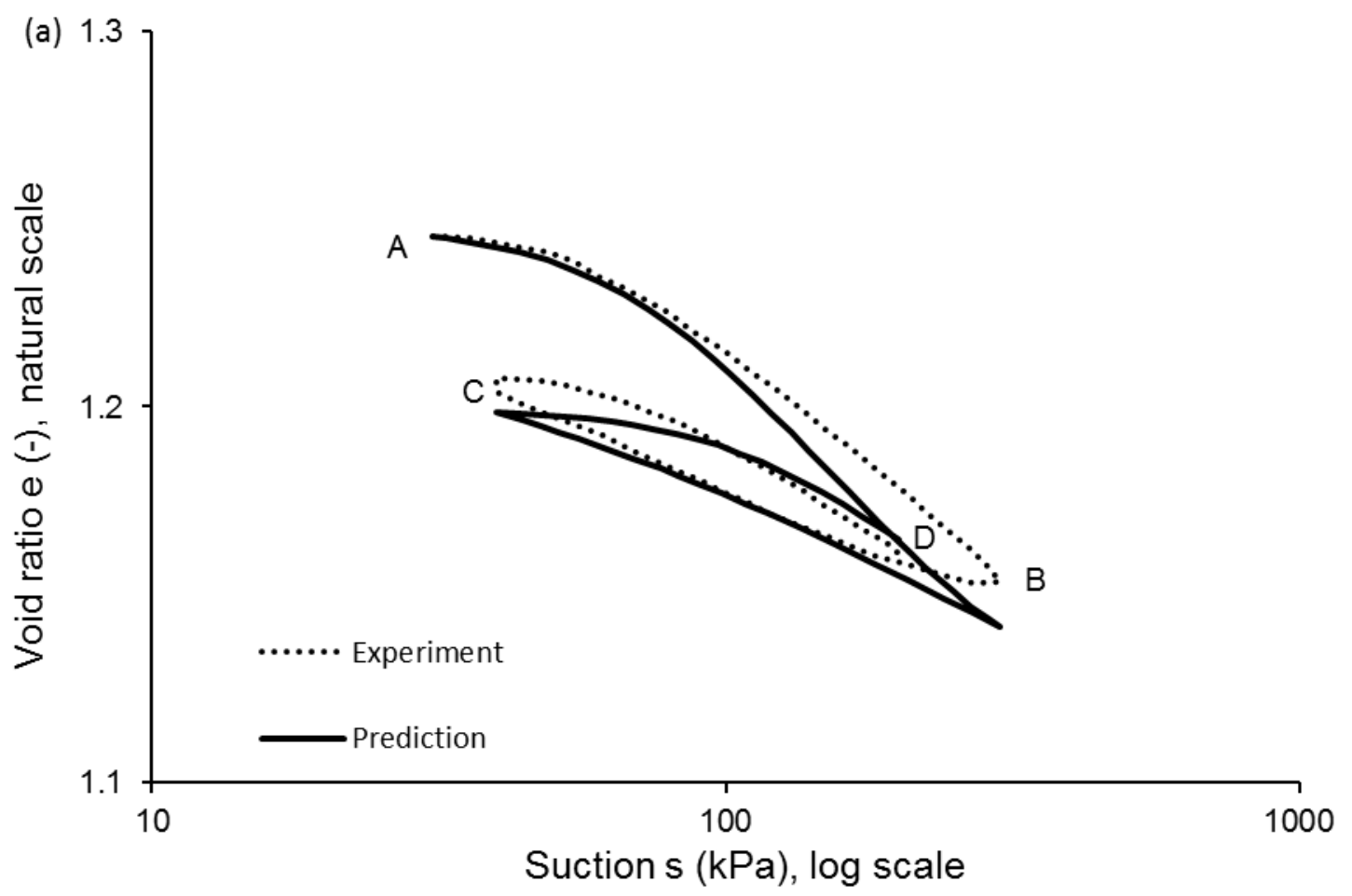




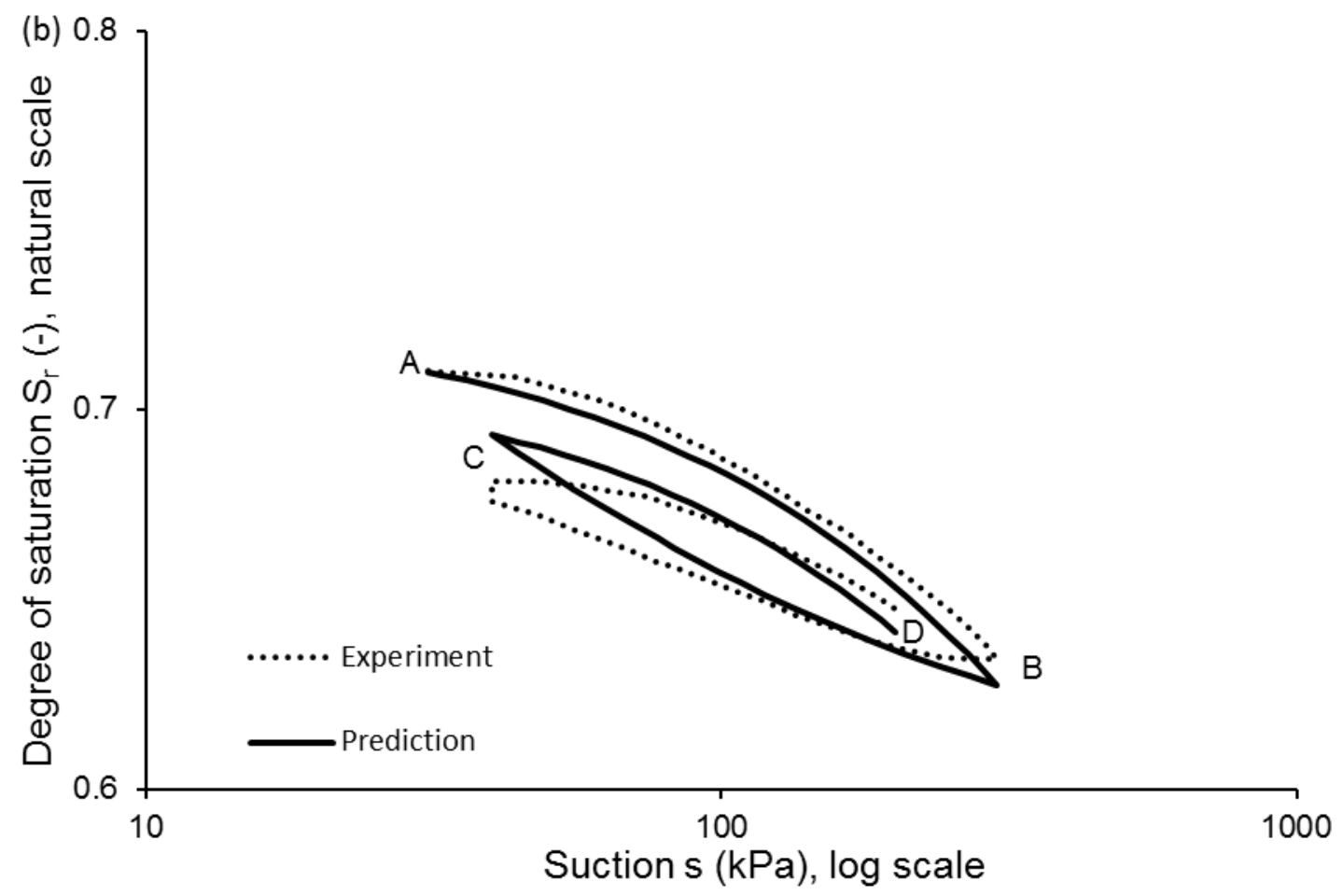

Figure 10. Validation against suction cycle at constant mean net stress of $10 \mathrm{kPa}$ on compacted kaolin: (a) void ratio vs suction and (b) degree of saturation vs suction (experimental data from Raveendiraraj, 2009)

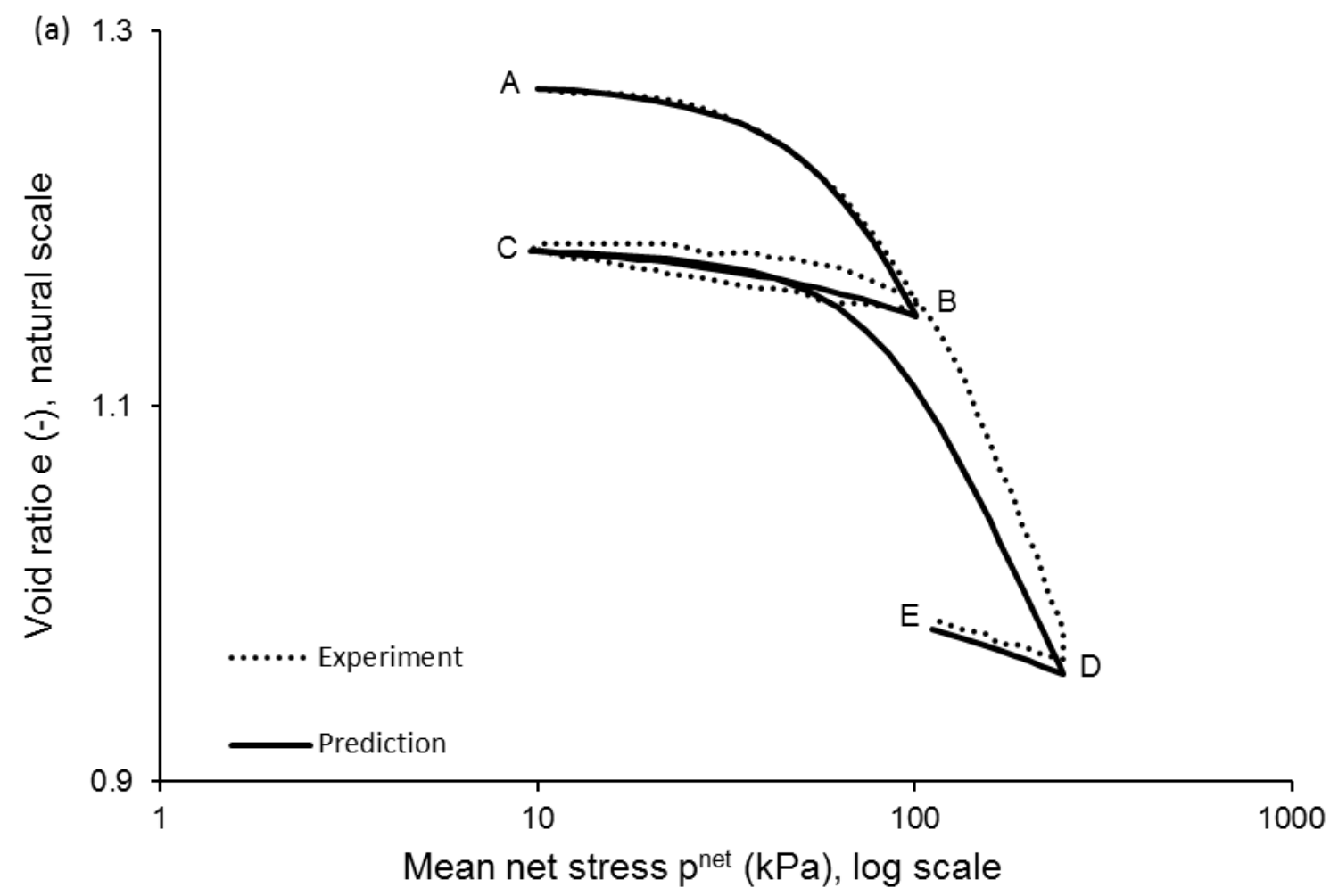




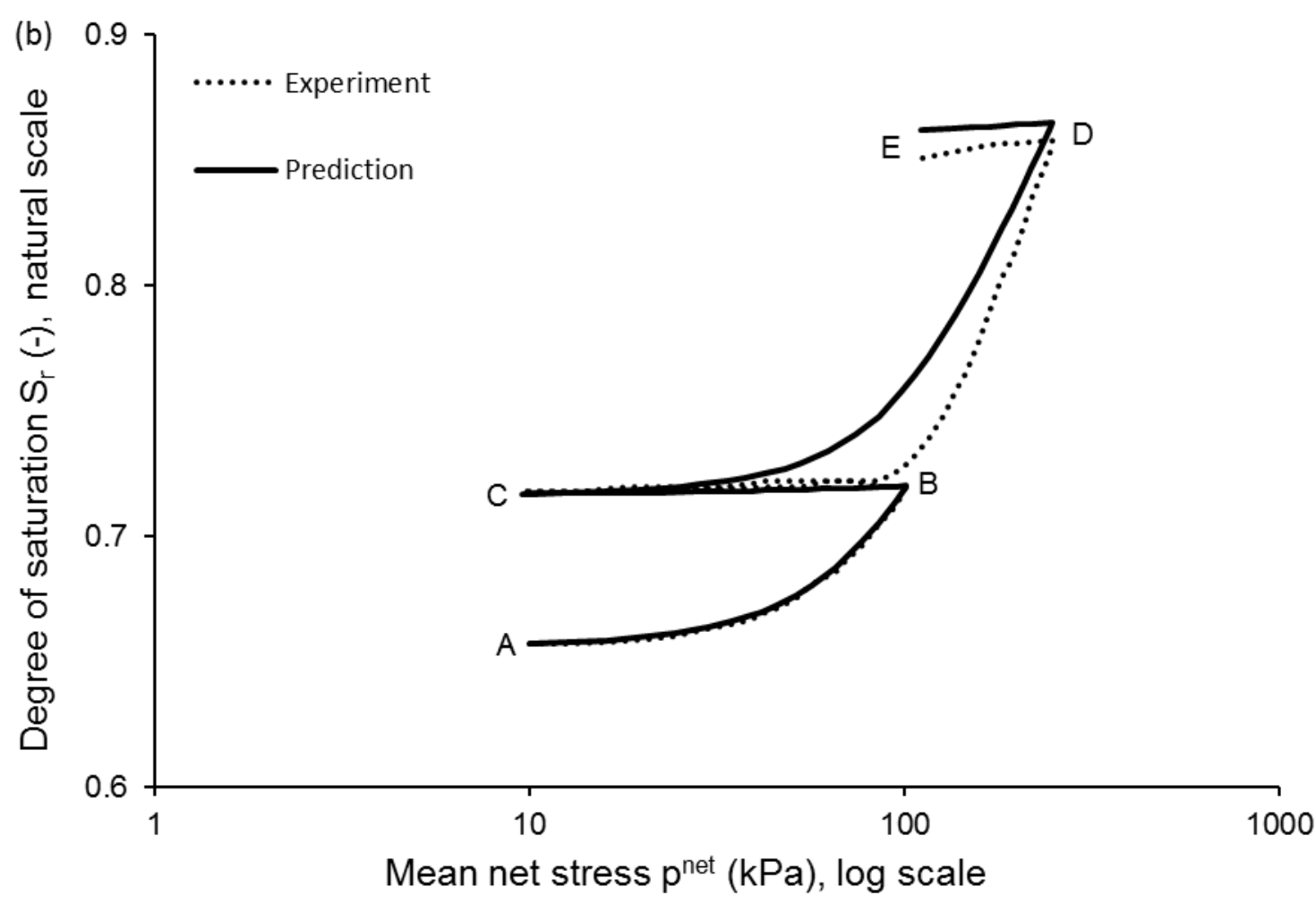

Figure 11. Validation against mean net stress cycle at constant suction of $200 \mathrm{kPa}$ on compacted kaolin/bentonite mix: (a) void ratio vs mean net stress and (b) degree of saturation vs mean net stress (experimental data from Sharma, 1998)

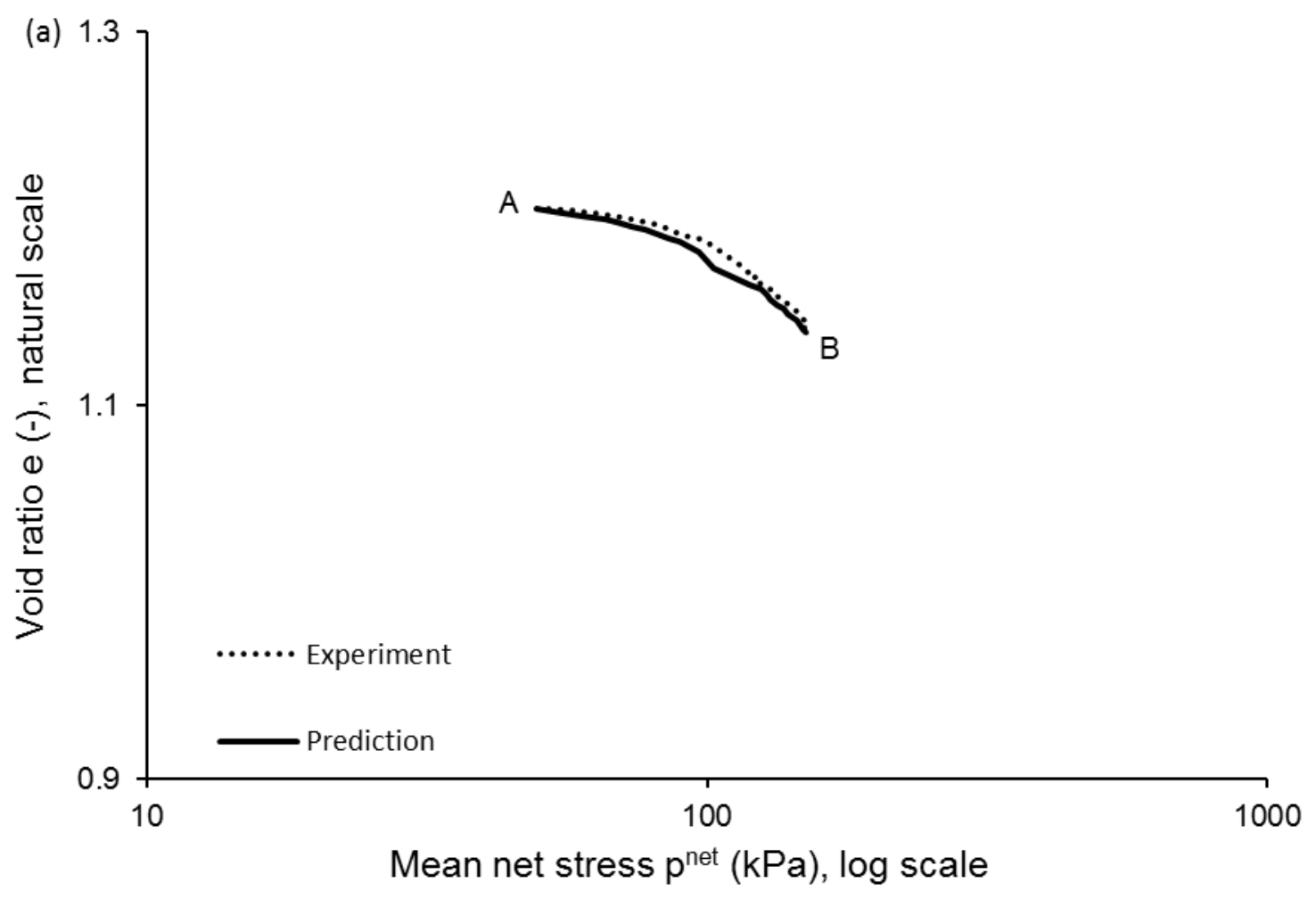




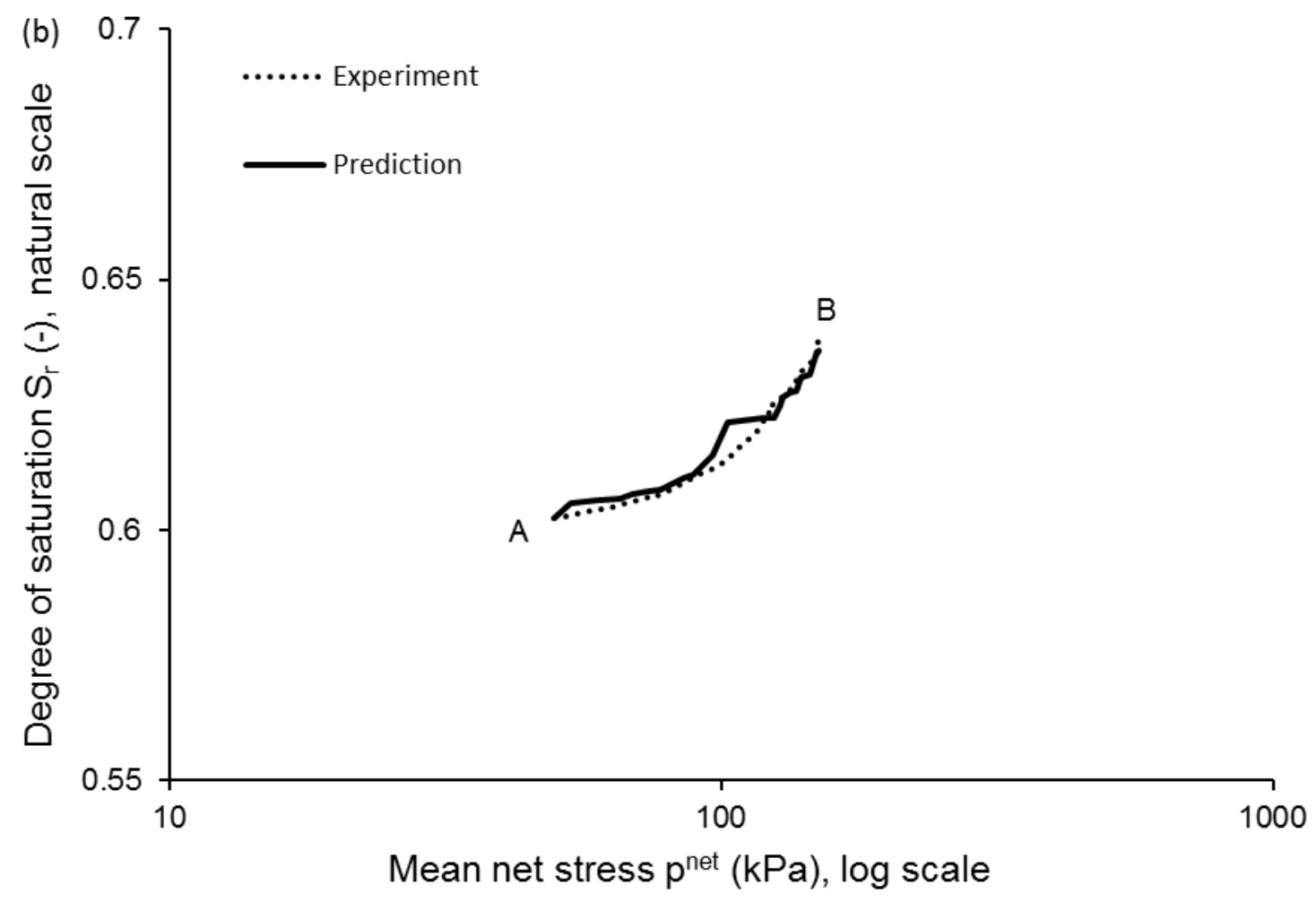

Figure 12. Validation against mean net stress increase at constant suction of $300 \mathrm{kPa}$ on compacted kaolin:

(a) void ratio vs mean net stress and (b) degree of saturation vs mean net stress (experimental data from Sivakumar, 1993)

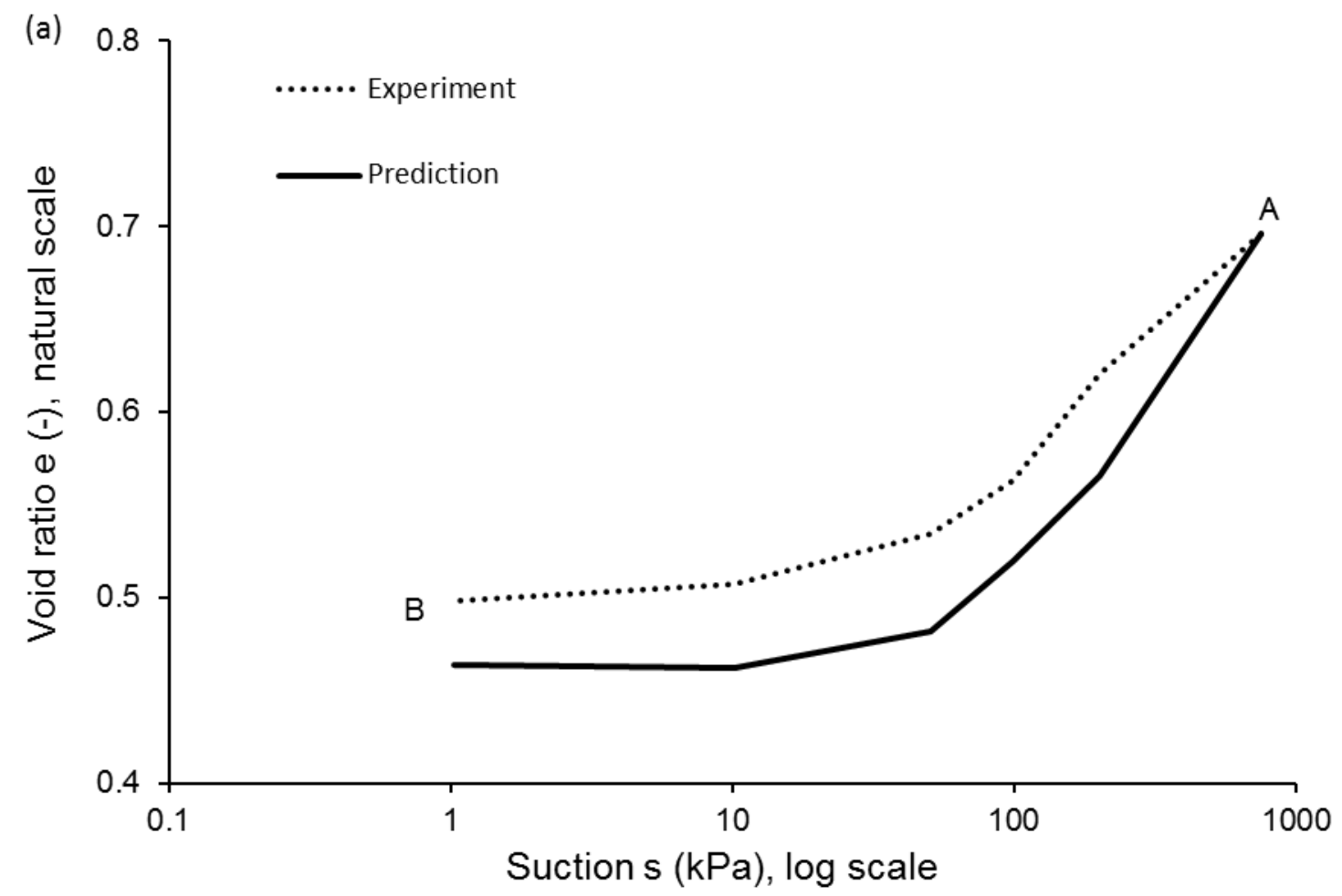




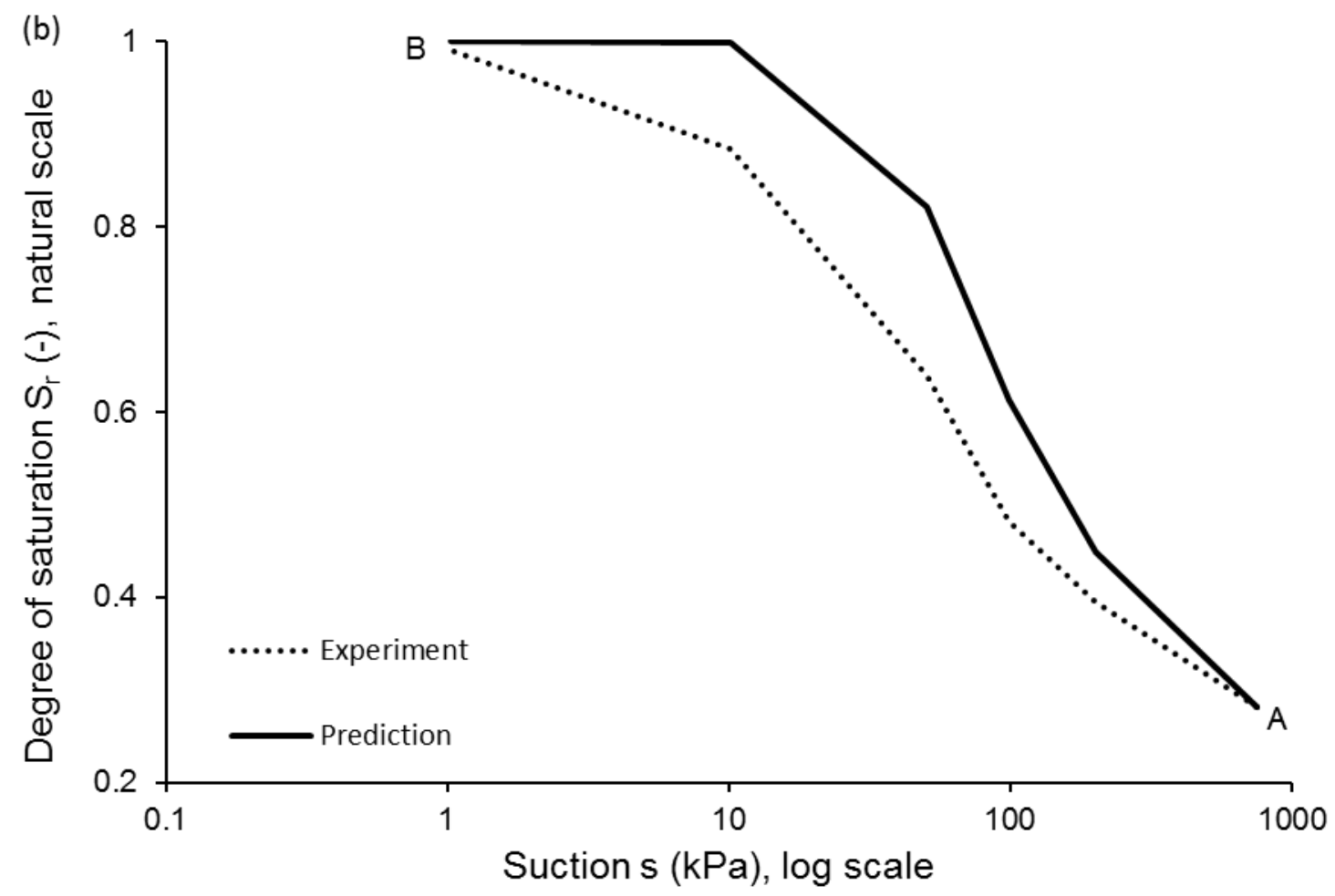

Figure 13. Validation against suction decrease at constant mean net stress of $400 \mathrm{kPa}$ on undisturbed loess silt: (a) void ratio vs suction and (b) degree of saturation vs suction (experimental data from Garakani et al., 2015)

\section{CONCLUSIONS}

The paper has presented a bounding surface model that predicts the hydromechanical behaviour of unsaturated soils subjected to isotropic loading-unloading and drying-wetting paths. The model couples the hydraulic law proposed by Gallipoli et al. (2015) with the mechanical law proposed by Gallipoli and Bruno (2017).

The hydraulic law is defined in terms of a single independent variable named the scaled suction, which is equal to the soil suction scaled by a power function of void ratio. The effect of volumetric deformation on the water retention behaviour is therefore taken into account through the incorporation of void ratio in the definition of the scaled suction. The hydraulic law consists of two closed-form equations for increasing and decreasing values of scaled suction, respectively. Each equation is defined up to an integration constant, 
whose value is defined by imposing a suitable boundary condition and which allows differentiating between individual paths.

Likewise, the mechanical law is defined in terms of a single independent constitutive variable named the scaled stress, which is equal to the mean average stress (also known as Bishop stress) scaled by a power function of degree of saturation. The effect of capillarity on mechanical behaviour is therefore taken into account through the incorporation of degree of saturation inside the definition of the scaled stress. Similar to the hydraulic law, the mechanical law consists of two closed-form equations for increasing and decreasing values of scaled stress, respectively. As before, each equation is defined up to an integration constant, whose value is defined by imposing a suitable boundary condition and which allows differentiating between individual paths.

Twelve model parameters are required to describe the coupled behaviour of unsaturated soils, including the occurrence of collapse-compression upon wetting, hydromechanical hysteresis and gradual yielding. Parameter values can be selected by either multi-variable fitting of experimental data or interpolation of individual parameters. The two calibration strategies have been employed in the present work, thus demonstrating the viability of both approaches.

After calibration, the coupled model has been validated against laboratory data covering a range of soil types from low plasticity or expansive clays to loess silts. Results show that the model is capable of accurately reproducing the hydromechanical behaviour of unsaturated soils and, in particular, the occurrence of swelling or collapse-compression upon saturation, the hysteresis during suction or stress cycles and the gradual variation of degree of saturation and void ratio without yielding discontinuities. Further work is however required to test the predictive capabilities of the proposed hydromechanical model against additional data and to extend the present formulation to a full constitutive framework that includes general non-isotropic stress states.

\section{AKNOWLEDGEMENTS}


The financial contribution of the "Agglomération Côte Basque Adour" through the project "Performances hygrothermiques et durabilité de briques de terre crue pour l'écoconstruction" is gratefully acknowledged.

\section{REFERENCES}

Alonso, E. E., Gens, A., \& Josa, A. (1990). A constitutive model for partially saturated soils. Géotechnique, 40(3), 405-430.

Bauer, E., Tantono, S. F., Cen, W., Zhu, Y., \& Kast, K. (2007). Hypoplastic modeling of the disintegration of dry and saturated weathered broken rock. In Theoretical and numerical unsaturated soil mechanics (pp. 11-18). Springer, Berlin, Heidelberg.

Brooks, R. N., \& Corey, A. T. (1964). Hydraulic properties of porous media. Colorado State University Hydrology Paper $N^{\circ} 3$.

Cui, Y.J., \& Delage, P. (1996). Yielding and plastic behaviour of an unsaturated compacted silt. Géotechnique, 46(2), 291-311.

Dangla, P., Malinsky, L., \& Coussy, O. (1997, July). Plasticity and imbibition-drainage curves for unsaturated soils: a unified approach. In Proc. 6th Int. Symp. Numer. Models Geomech. (NUMOG VI) (pp. 141-146).

Fredlund, D. G., \& Xing, A. (1994). Equations for the soil-water characteristic curve. Canadian geotechnical journal, 31(4), 521-532.

Fuentes, W., \& Triantafyllidis, T. (2013). Hydro-mechanical hypoplastic models for unsaturated soils under isotropic stress conditions. Computers and Geotechnics, 51, 72-82.

Gallipoli, D., Bruno, A. W., D’Onza, F., \& Mancuso, C. (2015). A bounding surface hysteretic water retention model for deformable soils. Géotechnique, 65(10), 793-804.

Gallipoli, D., \& Bruno, A. W. (2017). A bounding surface compression model with a unified virgin line for saturated and unsaturated soils. Géotechnique, 67(8), 703-712.

Gallipoli, D., Gens, A., Sharma, R., \& Vaunat, J. (2003a). An elasto-plastic model for unsaturated soil incorporating the effects of suction and degree of saturation on mechanical behaviour. Géotechnique, 53(1), 123-136.

Gallipoli, D., Wheeler, S. J., \& Karstunen, M. (2003). Modelling the variation of degree of saturation in a deformable unsaturated soil. Géotechnique, 53(1), 105-112.

Garakani, A. A., Haeri, S. M., Khosravi, A., \& Habibagahi, G. (2015). Hydro-mechanical behavior of undisturbed collapsible loessial soils under different stress state conditions. Engineering Geology, 195, 28-41.

Gudehus, G. (1995). A comprehensive concept for non-saturated granular bodies. In Proceedings of the first International Conference on Unsaturated Soils. Unsat-95, Paris, France 6-8 September 1995. Volume 2. 
Khalili, N., Habte, M. A., \& Zargarbashi, S. (2008). A fully coupled flow deformation model for cyclic analysis of unsaturated soils including hydraulic and mechanical hystereses. Computers and Geotechnics, 35(6), 872-889.

Mašín, D., \& Khalili, N. (2008). A hypoplastic model for mechanical response of unsaturated soils. International Journal for Numerical and Analytical Methods in Geomechanics, 32(15), 19031926.

Morvan, M., Wong, H., \& Branque, D. (2010). An unsaturated soil model with minimal number of parameters based on bounding surface plasticity. International Journal for Numerical and Analytical Methods in Geomechanics, 34(14), 1512-1537.

Niemunis, A. (2003). Extended hypoplastic models for soils (Vol. 34). Inst. für Grundbau und Bodenmechanik.

Raveendiraraj, A. (2009). Coupling of mechanical behaviour and water retention behaviour in unsaturated soils (Doctoral dissertation, University of Glasgow).

Russell, A. R., \& Khalili, N. (2006). A unified bounding surface plasticity model for unsaturated soils. International Journal for Numerical and Analytical Methods in Geomechanics, 30(3), 181212.

Sharma, R. S. (1998). Mechanical behaviour of unsaturated highly expansive clays (Doctoral dissertation, University of Oxford).

Sheng, D., Sloan, S. W., \& Gens, A. (2004). A constitutive model for unsaturated soils: thermomechanical and computational aspects. Computational Mechanics, 33(6), 453-465.

Sivakumar, V. (1993). A critical state framework for unsaturated soil (Doctoral dissertation, University of Sheffield).

Tarantino, A., \& Tombolato, S. (2005). Coupling of hydraulic and mechanical behaviour in unsaturated compacted clay. Géotechnique, 55(4), 307-317.

Van Genuchten, M. T. (1980). A closed-form equation for predicting the hydraulic conductivity of unsaturated soils 1. Soil science society of America journal, 44(5), 892-898.

Vaunat, J., Cante, J. C., Ledesma, A., \& Gens, A. (2000). A stress point algorithm for an elastoplastic model in unsaturated soils. International Journal of Plasticity, 16(2), 121-141.

Wheeler, S. J. (1996). Inclusion of specific water volume within an elasto-plastic model for unsaturated soil. Canadian Geotechnical Journal, 33(1), 42-57.

Wheeler, S. J., Sharma, R. S., \& Buisson, M. S. R. (2003). Coupling of hydraulic hysteresis and stress-strain behaviour in unsaturated soils. Géotechnique, 53(1), 41-54.

Wheeler, S. J., \& Sivakumar, V. (1995). An elasto-plastic critical state framework for unsaturated soil. Géotechnique, 45(1), 35-53. 
Zhou, C., Ng, C. W. W., \& Chen, R. (2015). A bounding surface plasticity model for unsaturated soil at small strains. International Journal for Numerical and Analytical Methods in Geomechanics, 39(11), 1141-1164. 